\section{A Precision Planter for Large Seeds in Small Plots}

\author{
Andrew M. Birmingham ${ }^{1}$, \\ Eric A. Buzby ${ }^{1}$, Donte L. Davis ${ }^{1}$, \\ Eric R. Benson ${ }^{2}$, \\ James L. Glancey ${ }^{3}$, \\ Wallace G. Pill ${ }^{4}$, Thomas A. Evans ${ }^{5}$, \\ Robert P. Mulrooney ${ }^{6}$, and \\ Michael W. Olszewski ${ }^{7}$
}

AdDitional INDEX words. mechanized planter, seeder

SumMary. A mechanical planter was developed to sow seed of baby lima beans (Phaseolus lunatus) in small plots. The mechanical seeder allowed small plots to be quickly and consistently seeded at a fixed spacing. Seeds were manually spread along a $10-\mathrm{ft}$ $(3.0 \mathrm{~m})$ base plate containing 50 holes of slightly larger diameter than the seed length and at the desired seed spacing [2.4 inches $(6 \mathrm{~cm})]$. Once all the holes were filled, a slider plate below the base plate containing holes of the same diameter and spacing, but which were slightly offset, was slid horizontally so that the holes of the base and slider plates aligned and the seeds dropped to the bottom of the furrow. Compared to manual planting, the mechanical planter increased the precision of seed placement and reduced the time needed to plant $\mathbf{5 0}$ seeds. The planter was easy to use and transport, and was inexpensive.

$\mathrm{R}$ esearchers at the University of Delaware conduct cultivar and lima beans for which a limited supply of seed is available. In these trials, multiple comparisons are included in the experimental design that require

Department of Bioresources Engineering, University of Delaware, Newark, DE 19717.

${ }^{1}$ Undergraduate student.

${ }^{2}$ Assistant Professor; to whom reprint requests should be addressed. E-mail: ebenson@udel.edu

${ }^{3}$ Associate Professor

4,5,6,7 Professor, Associate Professor, Extension Specialist, and $\mathrm{PhD}$ candidate, respectively, of the Department of Plant and Soil Sciences, University of Delaware, Newark, DE 19717.

Partial funding support for this research by the Delaware Department of Agriculture is appreciated. randomization of cultivars or seed treatments, often in adjacent rows so that traditional mechanical precision planters can not be used. The inappropriateness of such planters in such trials in small plots include: the inability to start and stop dispensing seeds at the plot boundaries, seed hoppers must contain more seed than the number dispensed for the planter to function properly, and seeds within the planter must be removed before a new row can be planted.

In our trials, we mark row locations on the prepared soil, 30 inches $(76.2$ $\mathrm{cm})$ apart and $20 \mathrm{ft}(6.1 \mathrm{~m})$ long. A furrow of 2 -inch $(5.1 \mathrm{~cm})$ depth is made by dragging a hoe along the row. The seeds are manually planted 2.4 inches apart in the furrow ( 100 seeds per row), covered with 1 inch $(2.5 \mathrm{~cm})$ of soil from both sides of the furrow, and the covered row compressed by walking. These in-row and between-row spacings comply with recommendations for lima beans (University of Delaware, 2004). Since this manual planting is both labor intensive and leads to poor seed spacing precision, we wished to develop a precision mechanical planter to reduce these drawbacks. Sanders (1994) summarized the limitations and results of mechanized precision seeding and described six types of precision seeders (belt, plate, vacuum, spoon, pneumatic, and grooved cylinder) with their associated advantages and disadvantages. These planters vary in their ability to singulate and precisely plant seeds, to plant seeds of various sizes, and in their gentleness of seed handling (important with respect to certain seed treatments). Planters designed specifically for small research plots have been developed for small grains (Engel et al., 2003; Wiseman et al., 1972) and for potato (Solanum tuberosum) seed pieces (Arsenault et al., 1996). However, we know of no precision planters developed for large-seeded vegetables for use in small plots.

The goal of this project was to build a precision seeder for large seeds (baby lima beans) in small plots that would precisely place seeds, and be easy to use, lightweight, and inexpensive.

\section{Materials and methods}

Apparatus. The planter was designed to sow 50 seeds simultaneously at 2.4-inch centers in a 10 - $\mathrm{ft}$-long row. The planter then would be refilled manually with seeds and moved over 
Fig. 1. Perspective view, with critical dimensions, of the precision planter designed for small plots. Seeds were spread manually along a 10 -ft $(3.0 \mathrm{~m})$ base plate containing 50 holes at the desired seed spacing. Once all the holes were filled, a slider plate below the base plate containing holes of the same diameter and spacing, but which were offset, was slid horizontally and the seeds dropped to the bottom of the furrow. 1 inch $=2.54 \mathrm{~cm}$.

the remaining $10 \mathrm{ft}$ of row, which then would be seeded.

The planter consists of a 7 -inch $(17.8 \mathrm{~cm}) \times 10$ - $\mathrm{ft}$ base plate with 1 -inch "legs" on each side that were formed by bending 14-gauge $(0.2 \mathrm{~cm}$ thick) aluminum alloy to form right-angles (Figs. 1 and 2A). The legs could be pushed into the soil to permit some variation in planting depth. Seed holes, nominally $9 / 16$-inch $(1.43 \mathrm{~cm})$ diameter, drilled into the base plate on 2.4-inch centers, fixed the seed spacing. A 1.5 -inch-wide $(3.81 \mathrm{~cm}) \times$ by $1 / 8$-inch-thick $(0.32$ $\mathrm{cm}$ ) nylon strip, drilled with holes of the same diameter and spacing as the base plate, was bolted to the base plate so that the holes in both the base plate and nylon strip were aligned. The nylon strip was sized to allow the seeds to rest within a well, holding the seeds directly above the holes in the base plate. $\mathrm{Ny}$ lon provided less friction to the seeds than aluminum alloy as the seeds were pushed along the trough. Bolted to the

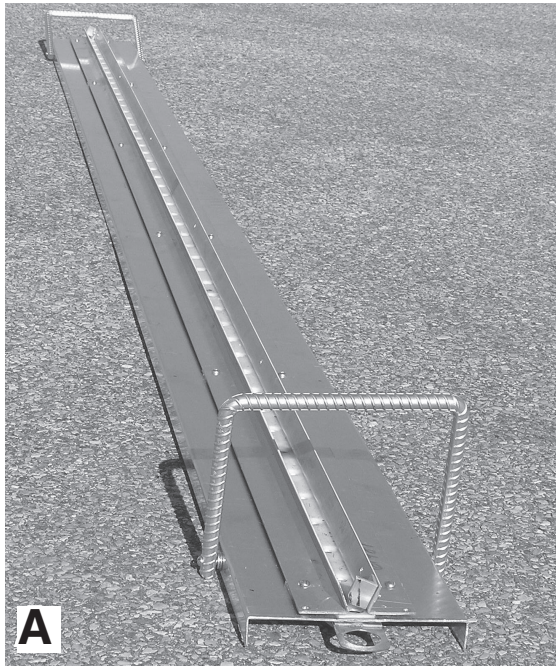

base plate and nylon strip were two l-inch-high trough walls constructed of 14-gauge aluminum alloy. Walls were 0.7 inch $(1.78 \mathrm{~cm})$ apart at the base and sloping outward at $14^{\circ}$ from vertical. The trough allowed seeds to be distributed easily along the planter. Hole size and spacing were for 'Maffei 15' lima beans but they will vary for other large-seeded crops.

A 1.5 -inch-wide $\times 10$-ft-long slider plate of 14-gauge aluminum alloy with holes of the same diameter and spacing as the seed plate was attached loosely to the underside of the base plate (Fig. 2B). A small handle attached to one end of the slider plate allowed for the plate's easy movement. Four slots $[1 \times 1 / 4$ inch $(2.5 \times 0.64$ $\mathrm{cm})]$ machined along each side of the slider plate allowed it to slide relative to the base plate. The slider plate was attached with 0.5 -inch $(1.27 \mathrm{~cm})$ no. 10 machine screws with nylock nuts, with one washer between the bottom

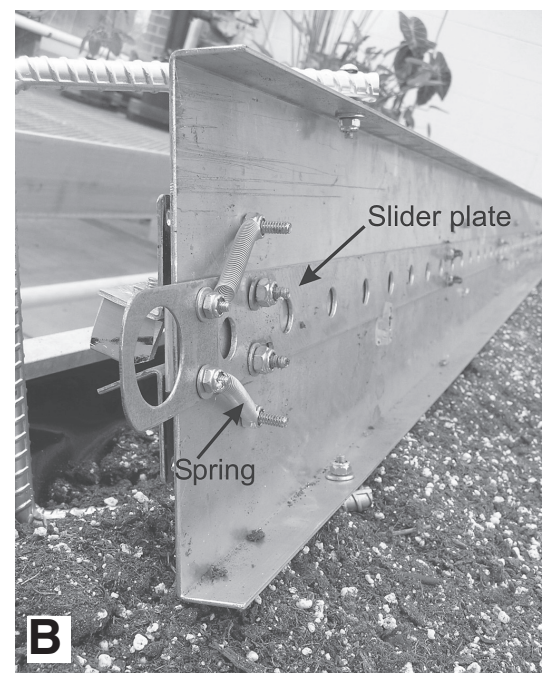

of the base plate and slider plate. The holes in the slider plate were offset by one hole diameter from the holes in the base plate. Two springs under tension at one end of the slider plate (Fig. 2B) held the slider plate in a position so that its holes were offset from those of the base plate. With the slider plate in an offset position, the holes were closed and seeds could not fall through. The completed apparatus weighed $17.3 \mathrm{lb}$ $(7.85 \mathrm{~kg})$ and contained about $\$ 100$ of materials. Approximate costs were: $\$ 85$ for aluminum alloy sheets, $\$ 10$ for the nylon base plate, and $\$ 5$ for machine screws, washers, and self-locking nuts.

To load the planter, 50 seeds were placed at one end of the trough and pushed by hand or with a paintbrush toward the other end of the trough, filling the wells in the base plate (Fig. 2C). When positioned over the furrow, the slider plate was pulled and the seeds dropped 1.8 inches $(4.57 \mathrm{~cm})$ through the aligned holes (base and slider plates) to the furrow bottom. The planter then would be positioned (using handles attached to each end of the base plate) over the remaining portion of the furrow so that it could be seeded.

Planting precision and time. Since seed size variation may affect the efficiency of the planter, seeds of 'Maffei 15' lima bean were divided into two groups, nonsorted and size-sorted. Five-hundred seeds were measured with a vernier caliper to have dimensions (mean $\pm \mathrm{SD}$ ) of length $(0.48 \pm 0.04$ inch $)$, width $(0.36 \pm 0.03$ inch $)$, and thickness $(0.18 \pm 0.02$ inch $)$ (12.192 $\pm 1.016,9.144 \pm 0.762$, and $4.572 \pm$ $0.508 \mathrm{~mm}$, respectively). Since seed

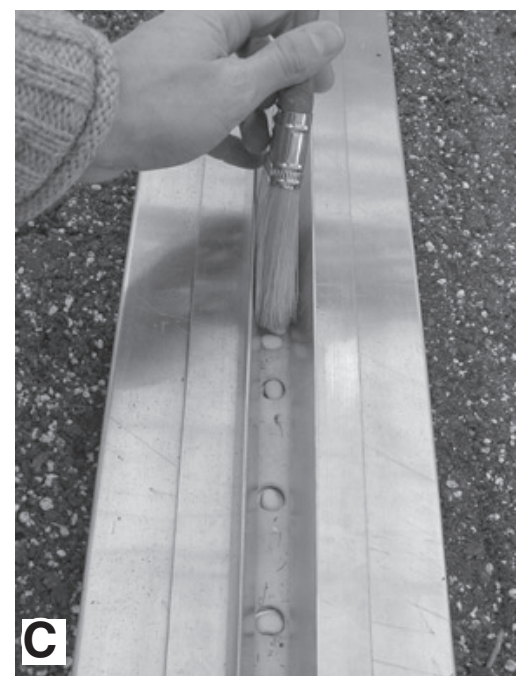

Fig. 2. Photographs of the planter: (A) overall view; (B) bottom view, showing the slider plate and pull handle and springs; and $(\mathrm{C})$ planter in use, showing the seeds being pushed along the base plate within the trough. 
length had the lowest coefficient of variation $(7.35 \%)$, sorted seeds were selected by measuring to be within 1 standard deviation of the mean length to give a range of 0.45 to 0.52 inch (11.430-13.208 mm), while the length range for nonsorted seeds was 0.44 to 0.56 inch (11.176-14.224 mm).

Five replications of 50 nonsorted and sorted seeds were sown manually and by using the planter into furrows prepared in soil of fine tilth. The time required to plant the 50 seeds was recorded and the distance between the center of each planted seed was measured using a ruler. These data were subjected to analysis of variance.

\section{Results and discussion}

Although seed spacing was unaffected by planting method, the coefficient of variation of seed spacing was decreased from $16.4 \%$ with the manual planting to $11.0 \%$ with mechanical planting (Table 1). Reducing the distance from the planter base to the furrow bottom from the 1.8 inch used in the present study by reducing the "leg" length or by pushing the planter farther into the soil undoubtedly would reduce the variation in planting precision by reducing the amount of seed bounce. Increasing the fineness of soil tilth in the furrow bottom likewise would reduce seed deflection after bouncing, and thus reduce variation in seed spacing.

The time required to plant 50 seeds was affected by the interaction of planting method and seed sorting (Table 1). Manual planting of 50 seeds planting, irrespective of seed sorting. While seed size-sorting had no effect on manual planting time, using sizesorted seeds reduced the time required to mechanically plant 50 seeds by $33 \%$, required more time than mechanical

from $105 \mathrm{~s}$ to $70 \mathrm{~s}$. The time necessary to size sort the seeds, however, is not included in the $70 \mathrm{~s}$. With nonsorted seeds there was a greater instance of two smaller seeds occupying the same hole in the base plate (average eight holes with doubles) than with sorted seeds (average three holes with doubles). The greater time required to sow 50 nonsorted seeds than sorted seeds reflected the additional time required to move a seed from each hole with two seeds to a vacant hole.

In developing the planter, several design features were modified. The trough walls were moved inward so that the bottom of the trough was only 0.1 inch $(2.54 \mathrm{~mm})$ wider than the hole diameter. This was necessary so that no seed could "avoid" a hole in the base plate as the seeds were pushed along it. The trough walls were extended to a height of 1 inch so that all 50 seeds could fit in the trough at one end of the planter without spilling out of the trough. Nylon replaced aluminum alloy at the bottom of the trough because it provided less friction as the seeds were pushed along the trough.

To reduce the frequency of double seeds accumulating within a well of the base plate, the hole diameter and depth must be only slightly greater than the seed length and thickness, respectively. For the nonsorted seed, the greater difference between the length of the smallest seed and the hole diameter [0.19 inch $(4.826 \mathrm{~mm})$ vs. 0.15 inch $(3.810 \mathrm{~mm})$ for the sorted seed] led to the higher percentage of double seed occupancy in the base plate holes and to the corresponding increased time for planting. The base plate hole depth (to the slider plate) of $6 \mathrm{~mm}$ was sufficiently shallow that two seeds (single seed thickness was $0.18 \pm 0.02$ inch) could not stack on top of each other

Table 1. Seed spacing and time required to plant 50 'Maffei 15' lima bean seeds as influenced by planting method (manual or machine) and seed size sorting.

\begin{tabular}{|c|c|c|c|c|}
\hline \multirow{2}{*}{$\begin{array}{l}\text { Planter } \\
\text { method }\end{array}$} & \multirow{2}{*}{$\begin{array}{l}\text { Seed size } \\
\text { sorting }^{z}\end{array}$} & \multicolumn{2}{|c|}{ Seed spacing ${ }^{y}$} & \multirow{2}{*}{$\begin{array}{c}\text { Time to plant } \\
\text { (s) }\end{array}$} \\
\hline & & Mean (inches) & CV (\%) & \\
\hline Manual & $\begin{array}{l}\text { No } \\
\text { Yes }\end{array}$ & $\begin{array}{l}2.35 \\
2.41\end{array}$ & $\begin{array}{l}16.6 \\
16.2\end{array}$ & $\begin{array}{l}140 \\
144\end{array}$ \\
\hline Machine & $\begin{array}{l}\text { No } \\
\text { Yes }\end{array}$ & $\begin{array}{l}2.40 \\
2.42\end{array}$ & $\begin{array}{l}11.2 \\
10.7\end{array}$ & $\begin{array}{r}105 \\
70\end{array}$ \\
\hline Significance & & & & \\
\hline $\begin{array}{l}\text { Planter method }(\mathrm{PM}) \\
\text { Seed sorting }(\mathrm{SS}) \\
\mathrm{PM} \times \mathrm{SS}\end{array}$ & & $\begin{array}{l}\text { NS } \\
\text { NS } \\
\text { NS }\end{array}$ & $\begin{array}{l}* * * \\
\text { NS } \\
\text { NS }\end{array}$ & $\begin{aligned} * * * \\
N S \\
* *\end{aligned}$ \\
\hline
\end{tabular}

${ }^{2}$ Seed size sorting: seed length for "No" $=0.44-0.56$ inch $(11.176-14.224 \mathrm{~mm})$, and for "Yes" $=0.45-0.52$ inch (11.430-13.208 mm).

y 1 inch $=25.4 \mathrm{~mm} ; \mathrm{CV}=$ coefficient of variation

ss, ${ }^{* *}, * * *$ Nonsignificant or significant at $P \leq 0.01$ or 0.001 , respectively. in the hole. Although developed for 'Maffei 15' lima bean seeds, the planter could be adapted for precision planting of other large-seeded species by changing the hole size and spacing in the base and slider plates. Hole depth in the base plate hole depth could be varied by selecting nylon of different thickness. To change the planter to accommodate a different species, the 12 lock-nuts securing the trough walls, nylon strip, and slider plate to the base plate would be removed. The new nylon strip and base plate would be inserted respectively on top and below the base plate, and the lock-nuts resecured.

With manual sowing, the sowing hand can hold only four to five seeds before it must be replenished with seeds from an envelope held in the other hand. Only about 3 feet $(0.9 \mathrm{~m})$ of row can be sown easily (without undue stretching) before the individual planting must move along the row and repeat the process. The repeated recharging of the sowing hand with seeds and the repeated movement along the row (with the planting individual having to stoop and straighten at each location) resulted in the greater time and labor input (data not collected) required to plant 50 seeds manually than mechanically (Table 1).

We conclude that the mechanical planter described increased the seed spacing precision and reduced the time required to sow 50 baby lima bean seeds compared to manual sowing. The machine could be adapted to accommodate large seeds of other species. The machine was easy to use and move (17.3 lbs), and was inexpensive (\$100 of materials).

\section{Literature cited}

Arsenault, W.J., H.W. Platt, E. Pippy and A. Cannon. 1996. A small plot potato planter. Canadian Agr. Eng. 38:145-147.

University of Delaware. 2004. Commercial vegetable production recommendations, Delaware. 2004. Ext. Bul. 137. Univ. of Delaware, Newark.

Engel, R.E., T. Fischer, J. Miller, and G. Jackson. 2003. A small-plot seeder and fertilizer applicator. Agron. J. 95:1337-1341.

Sanders, D.C. 1994. Precision seeding for vegetable crops. 8 June 2004. North Carolina Coop. Ext. <www.ces.ncsu.edu/depts/hort/ hil/hil-36.html>.

Wiseman, B.R., R. Johnson, N.W. Widstrom, and W.W. McMillian. 1972. A sorghum planter for small experimental plots. Agron. J. 64:557-558. 